Int. J. Electrochem. Sci., 14 (2019) $4420-4442$

International Journal of

ELECTROCHEMICAL

SCIENCE

www.electrochemsci.org

\title{
Performance of $(\mathrm{HEMIM})^{+}(\mathrm{CN})^{-}$and $(\mathrm{DMIM})^{+}(\mathrm{Cl})^{-}$as corrosion inhibitor of API 5L X52 steel in $\mathrm{HCl}$ medium
}

\author{
Mónica Corrales-Luna ${ }^{1}$,Tu Le Manh ${ }^{1,2,3}$, E.M. Arce-Estrada ${ }^{1 *}$ \\ ${ }^{1}$ Instituto Politécnico Nacional. ESIQIE, Departamento de Ingeniería en Metalurgia y Materiales. \\ UPALM, Ed. 7. CDMX, 07738. México. \\ ${ }^{2}$ Faculty of Materials Science and Engineering, Phenikaa Institute for Advanced study (PIAS), Phenikaa \\ University, Hanoi 100000, Vietnam \\ ${ }^{3}$ Phenikaa Research and Technology Institute (PRATI), A\&A Green Phoenix Group, 167 Hoang Ngan, \\ Hanoi 10000, Viet Nam \\ *E-mail: earce@ipn.mx
}

doi: $10.20964 / 2019.05 .31$

Received: 6 January 2019 / Accepted: 27 February 2019 / Published: 10 April 2019

Two ionic liquids, 1-(2-hydroxyethyl)-3-methylimidazolium dicyanamide (HEMIM) $)^{+}(\mathrm{CN})^{-}$and 1,3didecyl-2-methylimidazolium chloride $(\mathrm{DMIM})^{+}(\mathrm{Cl})^{-}$, were evaluated as corrosion inhibitors of the API 5L X52 in $0.5 \mathrm{M} \mathrm{HCl}$ using electrochemical method, weight loss, and surface characterization techniques. Gravimetric tests showed that the ILs display high corrosion protection efficiency, \% EI, (92 $\%$ and $97 \%$ ) with 100 and 5 ppm of $(\mathrm{HEMIM})^{+}(\mathrm{CN})^{-}$and $(\mathrm{DMIM})^{+}(\mathrm{Cl})^{-}$, respectively. Electrochemical tests showed that the $\% E I$ depends on the IL concentration and the temperature. The polarization studies showed that the ILs are mixed type inhibitors and the adsorption of the ILs on the API 5L X52 obeyed the Langmuir adsorption isotherm displaying chemical interaction between the steel and the IL. SEM and AFM verified a considerable reduction of the corrosion process after the addition of the ILs. Uv-vis also confirmed the interaction between ILs and steel. Theoretical quantum chemical calculation studies agree with experimental results. The adsorption energy of $(\mathrm{DMIM})^{+}(\mathrm{Cl})^{-}$on $\mathrm{Fe}(110)$ surface is higher than that of $(\mathrm{HEMIM})^{+}(\mathrm{CN})^{-}$, but both inhibitors are expected to bind strongly to the API 5L X52.

Keywords: Ionic liquid; corrosion inhibitor; API 5L X52 steel; electrochemical tests.

\section{$\underline{\text { FULL TEXT }}$}

(C) 2019 The Authors. Published by ESG (www.electrochemsci.org). This article is an open access article distributed under the terms and conditions of the Creative Commons Attribution license (http://creativecommons.org/licenses/by/4.0/). 